\title{
Caminos y automóviles en Bolivia: cambios, tendencias y correspondencias en el pasado reciente
}

Jorge M. Veizaga R.

Centro de Estudios de Población, Universidad Mayor de San Simón, Bolivia

Recibido: 25 de mayo de 2017. Aceptado: 11 de julio de 2017.

\begin{abstract}
Resumen
Este artículo explora la relación que han tenido los caminos y los automóviles en el caso boliviano en el pasado reciente. Partiendo de una caracterización general de los niveles y tendencias de la inversión pública en infraestructura de caminos, de la extensión de la red vial así como de los niveles de acceso al automóvil de parte de los hogares bolivianos, se indagan las dimensiones en que existen correspondencias en términos de las tendencias o de los niveles de acceso y disponibilidad de ambos. También se identifican las dimensiones en las que parecen existir contradicciones. Por un lado, se observa que existe una tendencia a una creciente proporción de hogares con automóviles, lo cual condice con el modelo de transición de la movilidad de Zelinsky que supone una mayor movilidad cuanto más "desarrollada" sea una sociedad. Por otro lado, se identifica un patrón de provisión de caminos que parece estar básicamente determinado por la política pública. El ámbito político-institucional y el de la infraestructura interactúan desencadenando una serie de procesos de reajuste en contextos tan diversos como el económico, cultural y social que van condicionando los procesos de desarrollo económico y social en Bolivia.
\end{abstract}

\section{Roads and cars in Bolivia: changes, trends and correspondences in the recent past}

\begin{abstract}
This paper explores relationships between roads and vehicles in the Bolivian context during the last couple of decades. Based on a broad depiction of levels and tendencies of: a) public investment in transport networks and b) the extent of those road networks as well as the access to automobiles of Bolivian households, this paper aims to identify correspondences and/or contradictions between: expansion of road networks, vehicle's availability and public investment. The study confirms that road networks are increasing significantly and this is happening in correspondence with the increase in
\end{abstract}

Palabras clave

Caminos

Automóviles

Bolivia

Inversión pública

Movilidad espacial

Palavras-chave

Caminhos

Carros

Bolívia

O investimento público

Mobilidade espacial

\section{Keywords}

Roads

Automobiles

Bolivia

Public investment

Spatial mobility 
vehicles' access. These tendencies support the mobility transition model developed by Zelinsky, which assumes that more development implies greater mobility. However, there also seems to be a contradiction between the already mentioned tendencies and the patterns of public investment. Finally, it is possible to verify that interactions between political, institutional context and infrastructural contexts have considerable impacts on economic, social and cultural processes, which in turn affect development dynamics in Bolivia.

\section{Introducción}

Este artículo explora la relación que han tenido los caminos y los automóviles en el caso boliviano en el pasado reciente. Por supuesto, dicha relación resulta bastante compleja y puede ser abordada desde diversas perspectivas: teóricas, metodológicas y/o disciplinarias y es por ello que este artículo no pretende de ninguna manera "agotar" la discusión en torno a la problemática en cuestión, por el contrario, tan solo se espera poder contribuir al debate aportando algunas reflexiones que se derivan del análisis del caso boliviano. Así, en lo que respecta a la metodología de este trabajo, vale la pena mencionar que se trata de un análisis empírico, basado en información secundaria de carácter oficial y de tipo general, acerca de los caminos y automóviles en Bolivia y que básicamente busca identificar correspondencias y/o contradicciones en la evolución de sus volúmenes y tendencias de crecimiento.

Aunque el análisis de las correspondencias y contradicciones ya mencionadas podría realizarse siguiendo diferentes perspectivas teóricas, en este caso, se ha optado por asumir como hilo conductor los supuestos, relaciones, dinámicas y procesos implícitos en el modelo de Transición de la Movilidad, formalmente planteado por Zelinsky (1971), el mismo que se recapitula en la segunda sección de este artículo, cuando se contextualiza la problemática en cuestión. La tercera sección ofrece una síntesis de las principales características de la economía, los asentamientos humanos, la infraestructura y -en general- de los procesos de desarrollo socio-económico en Bolivia. La cuarta y la quinta sección se refieren por separado a los dos elementos centrales de este trabajo y contienen una síntesis de la información acerca de sus niveles, tendencias y evolución en el tiempo. Por su parte, la sexta sección se concentra en la identificación de correspondencias y/o contradicciones y ofrece reflexiones iniciales acerca de las implicaciones del análisis empírico respecto de: 1) los procesos de desarrollo en el caso boliviano en particular y en el caso de los países en desarrollo en general, 2) respecto de las posibilidades y limitaciones del modelo de la transición de la movilidad (y -por consiguiente- de las perspectivas teóricas vinculadas) para comprender ciertos procesos de movilidad socio-espacial.

\section{Algunos aspectos de la problemática relación entre caminos y automóviles}

Tal como ya se ha mencionado, la relación entre caminos y automóviles implica una compleja serie de procesos sociales, económicos, territoriales, tecnológicos, culturales, institucionales y políticos entre otros. Dicha relación puede además ser considerada desde diversas perspectivas teóricas, metodológicas y disciplinarias; desde la historia, la antropología, la economía, la planificación urbana y la ciencia política por mencionar algunas disciplinas (Brown et al., 2009). En efecto, el estudio de la relación entre automóviles y caminos, hace alusión entre otras cosas, al desarrollo histórico de formas, medios, sistemas, técnicas y tecnologías que han intentado 
atender las demandas de movilidad espacial de individuos, grupos humanos, sociedades, civilizaciones y -en general- de toda la humanidad en diferentes contextos espacio-temporales. Desde esta perspectiva, las especificidades y los usos actuales del automóvil y de los caminos, estarían reflejando una compleja historia de inversiones de recursos (tanto públicos como privados), avances técnicos y tecnológicos, procesos de elección, preferencias, adaptación y apropiación de los grupos humanos respecto del automóvil que - por tanto- ya no puede ser considerado como un mero artefacto electro-mecánico sino más bien como un producto socio-cultural que ha llegado a ser calificado como uno de los rasgos más relevantes de las sociedades contemporáneas (Banco Mundial, 1987).

Desde una perspectiva más técnica, el automóvil y los caminos serían los elementos centrales de un sistema de movilidad socio-espacial que podría ser considerado en la actualidad como la principal alternativa para atender las necesidades de movilidad espacial de la gran mayoría de las sociedades en el mundo. En todo caso, el sistema del automóvil parecería no competir con los sistemas de transporte aéreo ni marítimo, en cambio, se podría decir que existe cierto grado de competencia con el sistema ferroviario y esto se debe específicamente a que ambos sistemas operan en escalas geográficas similares. En cualquier caso, dicha competencia varía en intensidad de acuerdo al contexto social de que se trate.

Desde sus inicios y en su evolución en el tiempo, el automóvil ha generado impactos significativos en los sistemas económicos, en los patrones residenciales y en la organización de las sociedades en general (Rode y Floater, 2014). La importancia de la economía del petróleo puede ser considerada como un resultado de la consolidación del sistema del automóvil. La expansión del tamaño de las ciudades ha sido identificada como uno de los hitos en el desarrollo urbano y ésta suele ser explicada como un resultado del automóvil (Butler, 1994; Rode y Floater, 2014).

Aunque los elementos básicos del sistema de transporte en cuestión sean el automóvil y los caminos, es importante tener en cuenta que existen otros elementos también esenciales, los cuales podrían ser clasificados en -al menos- dos grandes grupos: a) aspectos político-institucionales y b) aspectos técnico-tecnológicos.

»Aspectos político-institucionales:

» Reglamentos, normas, códigos, leyes.

" Agentes responsables de administrar, controlar.

" Usos del automóvil.

" Políticas públicas (inversión, etc.).

»Aspectos técnico-tecnológicos:

» Tecnología de construcción de caminos.

"Sistemas de gestión de caminos.

" Organización de caminos en redes (jerarquías, etc.).

» Mercado de automóviles.

»Sistemas de aprovisionamiento de combustible.

»Capacidades y logística para el mantenimiento de los automóviles.

" Reglamentación de la tenencia y uso de automóviles.

" Agentes responsables de diseñar, administrar, controlar.

Por supuesto, todos los aspectos y/o elementos que hacen al sistema se vinculan estrechamente, además, éstos a su vez tienen mucho que ver con otros procesos, estructuras y dinámicas más generales: políticas, ideologías, culturas productivas, etc. Así, para comprender mejor el contexto en el que se interrelacionan los sistemas de transporte con las estructuras sociales, resulta conveniente proseguir el 
estudio asumiendo alguna perspectiva teórica específica, a partir de la cual sea posible reflexionar de manera más ordenada y provechosa, las especificidades y dinámicas del objeto de estudio. Para efectos del estudio del sistema automóvil -caminos, existen diversas propuestas y modelos teóricos que podrían ser utilizados y en tal sentido es necesario reconocer que siempre existe algún grado de arbitrariedad en la elección de una u otra perspectiva teórica-.

En el caso de este estudio y asumiendo la perspectiva -relativamente más ampliade los estudios del desarrollo, se parte de uno de los supuestos fundamentales que subyacen a la lógica de los sistemas de transporte. Así, considerando que la búsqueda del desarrollo (generalmente caracterizado por el crecimiento económico y el mejoramiento de las condiciones de vida de la población), es uno de los elementos centrales en los procesos sociales (en la actualidad e históricamente) (Cypher y Dietz, 2004), se ha supuesto y se ha procurado que el desarrollo de los sistemas de transporte y en particular, el desarrollo del sistema del automóvil, contribuya a incrementar las posibilidades, y mejore los procesos de, producción, distribución y consumo de bienes. Es decir, facilitando y optimizando el acceso a recursos, ampliando el área de distribución y al mismo tiempo, facilitando el traslado de la fuerza de trabajo, el sistema del automóvil jugaría un papel importante en los procesos socio-económicos, en particular, en los últimos tiempos.

Naturalmente, se han realizado serios cuestionamientos respecto de tales supuestos y existen argumentos que contradicen el rol que se supone juegan los sistemas de transporte en general (véase por ejemplo: Browne, 1972). Al respecto, y más específicamente, en el caso de los nuevos caminos que conectan a comunidades rurales con las grandes ciudades, por un lado, se ha asegurado que dichos caminos promueven el desarrollo de tales comunidades mientras que por otro lado, se ha argumentado que dichos caminos sirven más bien como medio para establecer sistemas productivos y comerciales de explotación y para trasladar el valor generado en la periferie hacia los centros económicos del sistema de producción capitalista (Parpart y Veltmeyer, 2004).

Considerando lo expuesto, en este trabajo se asume la existencia de un sistema de producción de tipo capitalista que ha ido expandiéndose históricamente por todo el mundo. Junto a la expansión de dicho sistema, también se han expandido las preocupaciones acerca de la necesidad, las posibilidades y los derechos de todos los grupos humanos, de acceder y disfrutar de ciertas condiciones materiales de vida, es decir, de ciertos niveles de desarrollo que se espera mejoren constantemente. Una de las formas en que esta perspectiva teórica del desarrollo ha sido operacionalizada, es a través de la teoría de la modernización que en esencia propone la existencia de una tendencia secular en que las sociedades pasan de ser tradicionales, sub-desarrolladas y agrícolas y llegan a ser sociedades modernas, desarrolladas e industriales (Germani, 1971). Las transiciones han tenido lugar de manera heterogénea pero convergente (CELADE, 1996). En muchos casos, esta teoría ha sido cuestionada en tanto se han verificado trayectorias complejas, rezagos persistentes y otros cambios no esperados.

En todo caso, esta perspectiva teórica no solamente ha sido actualizada a partir de otras teorías como la de la globalización (Bowles, 2004; Petras y Veltmeyer, 2000) sino que también ha sido apoyada por diversas teorías específicas tal y como es el caso de la teoría de la transición de la movilidad, cuyo principal exponente ha sido Wilbur Zelinsky (1971) quien desarrolló un modelo que explica la movilidad como resultado de la interacción entre la evolución de las demandas de las sociedades en sus distintas fases de desarrollo y el avance tecnológico y puede ser descrito a través de una serie de estrategias que implican patrones de movilidad que se suponen son regulares y que corresponden a ciertas etapas del desarrollo de cada sociedad. 
Aunque el citado modelo implica varios elementos y fases, es posible destacar como argumento central la idea de una creciente y cada vez más compleja movilidad de la población. En efecto, cuanto más desarrollada sea una sociedad, mayor será la necesidad de movilidad y por tanto, mayores serán los flujos no solamente entre los centros que conformen el sistema de asentamientos humanos sino también al interior de éstos.

A partir del modelo en cuestión, este trabajo se concentra en evaluar si en el pasado reciente se ha verificado un incremento en los medios de movilidad y esto implica, entre otras cosas, que se haya incrementado el volumen de automóviles y el acceso a éstos, así como la infraestructura caminera. Por supuesto, el análisis de la evolución y las tendencias en ambos elementos deberá ser considerado cautelosamente en sus implicaciones respecto de la movilidad en general. Por lo tanto, independientemente de que se corrobore o no la hipótesis de la transición de la movilidad, es necesario considerar que existen diversos aspectos adicionales que deben ser estudiados con mayor profundidad y desde diferentes perspectivas teóricas.

En lo que respecta a la estrategia analítica, se ha optado por utilizar un modelo de mercado a partir del cual se ha estructurado el análisis, considerando que la relación entre caminos y automóviles puede ser comprendida como la relación que existe entre la oferta y la demanda de un bien, respectivamente. Por supuesto, se comprende que la analogía de la problemática en cuestión con el mercado no es la única ni la mejor y que -por lo mismo- existen varios aspectos respecto de los cuales el análisis, de los caminos como oferta y de los automóviles como demanda, deriva en mayores cuestionamientos antes que en mejores comprensiones del objeto de estudio. Por otro lado, también es necesario admitir que un abordaje excesivamente economicista podría sugerir antes que nada algún sesgo no solamente teórico sino también ideológico con lo cual se corre inevitablemente el riesgo de retomar una larga serie de controversias meta-teóricas. Por lo expuesto, la estrategia analítica asumida debe ser considerada únicamente como un recurso que permite organizar el análisis y la argumentación (cf. Salerno, 2012).

\section{Algunas consideraciones acerca del caso boliviano}

A partir de ciertas consideraciones acerca de la realidad boliviana, esta sección tiene el objetivo de contextualizar el análisis de la problemática general, de modo tal que los hallazgos del estudio puedan ser mejor comprendidos y valorados. Al respecto, es importante tener en cuenta que al estudiar el caso boliviano es posible identificar ciertas dimensiones que podrían ser considerados "comunes" a un conjunto mayor de casos (países, regiones, etc.) y en ese sentido, el caso boliviano correspondería a una muestra y los hallazgos podrían ser eventualmente generalizados con ciertas precauciones. Por otro lado, el caso boliviano posee ciertas particularidades a la luz de las cuales -exclusivamente- se podrían comprender ciertos aspectos de la problemática estudiada.

Considerando lo expuesto, esta sección aborda dos grandes áreas: 1) los procesos de desarrollo social y económico desde una perspectiva general y 2) los aspectos específicos de la realidad boliviana relacionados con la problemática de automóviles y caminos.

\section{El conjunto de procesos de desarrollo económico y social en Bolivia}

En términos de desarrollo económico social, los indicadores calculados para Bolivia corroboran su condición de atraso respecto del conjunto de países en el mundo no solamente en lo que se refiere al desarrollo humano o las condiciones materiales de vida sino también en relación con otras dimensiones tales como la salud, los derechos humanos y -sobre todo- en términos del desarrollo económico (World Bank, 2015). 
Así, a pesar de los significativos avances experimentados en materia económica en la última década (Bolivia, 2015), Bolivia sigue siendo considerada como país "en vías de desarrollo" o simplemente, en desarrollo. Son varias las opiniones que caracterizan la economía boliviana en términos de un persistente modelo primario-exportador, es decir, orientado a la explotación de recursos naturales para producir y exportar materias primas (Iturralde y Francke, 2013). El sector industrial tiene una participación limitada en la economía mientras que el sector comercial y de servicios es cada vez más grande ya que concentra una proporción creciente de la fuerza de trabajo, sin embargo, sus actividades económicas se caracterizan por ser de baja productividad, de tipo informal y en precarias condiciones laborales (Gray Molina, 2004; Veizaga, 2014).

$\mathrm{Al}$ evaluar los procesos de desarrollo en Bolivia históricamente, es posible identificar algunas fases o puntos críticos que se han interpretado como parte de ciclos económicos y políticos. De cualquier forma, la evaluación final no cambia sustancialmente persistiendo la imagen de Bolivia como un país históricamente rezagado (Laserna, 2012). En lo que concierne a la teoría de la modernización y más específicamente, en términos de la así denominada "Teoría de la Transición Demográfica", las evaluaciones realizadas caracterizan a Bolivia como un caso de "plena transición", es decir, habiéndose observado claros descensos en los niveles de mortalidad y fecundidad así como niveles relativamente elevados de urbanización, alfabetismo y otros, la sociedad boliviana reúne las condiciones demográficas correspondientes al proceso de modernización (CELADE, 1996).

No obstante lo arriba expresado, es importante tener en cuenta que ni el modelo de la transición demográfica puede ser considerado como una fórmula aplicable a todos los casos ni la población boliviana puede ser considerada como un todo homogéneo; por el contrario, se han identificado variaciones significativas entre diversos grupos poblacionales, lo cual pone en duda cualquier generalización respecto de la transición demográfica a nivel nacional. En cualquier caso, apenas es posible afirmar que Bolivia parece tender paulatinamente hacia la trayectoria general marcada por el modelo de la transición demográfica y por ende, hacia la modernidad o -al menos- hacia cierto tipo de modernidad.

\section{Especificidades del caso boliviano en relación al sistema del automóvil y su correspondiente infraestructura}

Tal como ya se ha indicado, siendo que el patrón económico se define como primarioexportador, cobran especial importancia los elementos que posibilitan la exportación de materias primas, es decir, tanto la infraestructura y logística orientada al transporte de carga, como las actividades (unidades económicas) que realizan los servicios de transporte.

Por un lado, es preciso mencionar que no existe un sistema de transporte ferroviario integrado y algunas de las porciones que funcionan, tienen un desempeño muy limitado (Sharp, 2005). Por consiguiente, el desarrollo de la infraestructura requerida se ha concentrado en la estrategia de establecer "corredores bi-oceánicos", es decir, una red de carreteras que conecte las redes vecinas en las fronteras occidentales y orientales del país para hacer posible la circulación del transporte de carga entre Perú y Chile por un lado y el Brasil por el otro, lo que resultaría en una conexión entre los puertos del Pacífico y los del Atlántico (ABC, 2017).

En congruencia con la estrategia de vinculación ya descrita pero también debido a otras varias razones, el sistema de asentamientos humanos en Bolivia se ha consolidado a partir de un eje urbano nacional conformado por tres conglomerados 
urbanos que en la actualidad ya son considerados como zonas metropolitanas: La Paz, Cochabamba y Santa Cruz, estando localizada la primera en el extremo occidental, la segunda en el centro geográfico del país y la última en el extremo oriental. Así, el sistema urbano nacional tiene un eje articulador constituido por tres grandes metrópolis que concentran población, recursos e infraestructura; un eje en relación del cual se organizan los flujos de mercancías, personas, recursos, etc. (cf. Lavayén y Veizaga, 2004).

Finalmente, un aspecto que vale la pena destacar es el referido a la acelerada expansión de las ciudades, en particular, de los ya mencionados conglomerados metropolitanos. En efecto, si bien podría decirse que la expansión urbana se acelera drásticamente a mediados de la década de los ochenta del siglo pasado, en un contexto de profunda crisis económica; dicha expansión ha seguido la tendencia inicial, consolidando consecuentemente extensas zonas periféricas de tipo marginal, con viviendas precarias y reflejando un patrón de expansión horizontal de baja densidad que incluye además una serie de problemas urbanísticos (Rocha, 2010).

La expansión de las ciudades ha implicado la necesidad de adaptar los sistemas de transporte tanto público ${ }^{1}$ como privado, extendiendo rutas, generando nuevas líneas de manera casi espontánea y -por tanto- de manera ineficiente. La expansión urbana también ha generado cierta presión sobre los diferentes niveles de gobierno para la implementación de servicios básicos y -por supuesto- para la construcción y mejoramiento de los caminos, carreteras, avenidas, calles, etc., las cuales se han construido sobre escasas bases de planificación (Rocha, 2010).

Por lo expuesto en esta sección es posible observar que el caso boliviano guarda mucha similitud con un amplio conjunto de países clasificados como "en vías de desarrollo" y que en esos términos puede ser considerado como un caso a partir del cual sería posible proponer cierta generalización de los hallazgos de este estudio. Por otro lado también se ha podido ver que existen características particulares en la estructura económica, en la organización del sistema de asentamientos humanos y en los procesos de expansión urbana que podrían estar incidiendo en una mayor demanda de caminos y automóviles.

\section{Procurando más caminos: la evolución de la "oferta"}

Tal como ya se ha explicado, la propuesta de analizar los caminos como la oferta en un mercado de "movilidad" implica básicamente suponer que todos los caminos se conciben y se concretan teniendo como principal finalidad, ser utilizados por los automóviles. En ese sentido, el análisis de la oferta se orienta a conocer y comprender las características que asume el conjunto de caminos en términos de su extensión, densidad y otras características no solamente físicas sino también técnicas y tecnológicas pero también en términos de la lógica según la cual se organizan y del contexto institucional en el marco del cual el conjunto de caminos se planifica y se gestiona. Considerando lo expuesto, esta sección caracteriza la oferta de movilidad en Bolivia en función de ciertos aspectos tanto técnico-tecnológicos como políticoinstitucionales, enfatizando en los procesos y tendencias de cambio verificadas en el pasado reciente.

\section{Aspectos técnico-tecnológicos relativos al sistema vial boliviano}

En la actualidad, el conjunto de caminos en Bolivia -como en la mayoría de los países en el mundo- se organiza bajo una lógica sistémica que en lo concerniente a la
1. En el caso boliviano, el sistema de transporte público corresponde principalmente a los servicios de transporte provisto por asociaciones y sindicatos que se organizan con apego a la normativa general pero siguiendo sus propias reglas las cuales - de manera general - reflejan lógicas de tipo corporativo (Nogales, 1985). 
infraestructura, la define como una red jerárquicamente estructurada, estableciendo estándares técnicos y tecnológicos que rigen su construcción y/o mantenimiento y que están orientados en última instancia a asegurar ciertos niveles de eficacia y eficiencia. La Ley General de Transporte (No 165), promulgada el 16 de agosto de 2011 (Bolivia, 2011) se constituye en un elemento clave orientado a organizar y regular los diferentes actores y procesos del sector del transporte en el país.

En consecuencia, la red de vial en Bolivia está conformada por tres conjuntos que podrían ser considerados como "subsistemas" y que corresponden a las redes: a) nacional, b) departamentales y c) locales - municipales. La citada Ley General de Transporte, clasifica las carreteras en cuatro tipos, siendo que los dos últimos corresponderían a la red local-municipal.

\section{La red nacional o fundamental}

La red fundamental ha sido usualmente definida como aquella formada por: 1) las vías que vinculan las ciudades capitales de los departamentos y 2) permiten la vinculación de carácter internacional, conectándose con las carreteras principales existentes de los países limítrofes (Servicio Departamental de Caminos, 1999:26-27).

De acuerdo con la información oficial de la Administradora Boliviana de Carreteras (ABC, 2017), la red vial fundamental de Bolivia tiene una longitud $15.963 \mathrm{~km}$, al interior de la cual, además, es posible identificar cinco "corredores" carreteros que representan la infraestructura a partir de la cual se pretende concretar la estrategia de los corredores bioceánicos ya mencionada previamente. La Figura 1 muestra el emplazamiento de los citados corredores en el territorio nacional.

Para tener una idea de las tendencias de cambio en la red vial fundamental, es importante mencionar que la longitud de la red en 2001 era de $10.401 \mathrm{~km}$, en 2008 se reportó que ésta se había extendido en algo más de cinco mil kilómetros, alcanzando los $16.029 \mathrm{~km}$, lo cual representa un incremento del 54\%, proporción que ha sido interpretada como un indicador de uno de los éxitos más significativos del gobierno del Movimiento Al Socialismo - MAS (ABC, 2008) ${ }^{2}$. En 2008, se ha reportado también la distribución de la red vial fundamental según tipo de vía y según departamento (Cuadros 1 y 2). Por un lado se puede observar que si bien la red vial fundamental se ha extendido respecto de 2001, ésta todavía tiene una importante proporción de vías de regular y deficiente calidad (39 y 30 por ciento respectivamente) lo cual refleja importantes limitaciones en su funcionalidad a nivel general.

Cuadro 1. Bolivia - 2008, distribución de la red vial fundamental según tipo de vía. Fuente: Elaboración propia con datos de ABC (2008)

\begin{tabular}{|l|c|c|}
\hline Tipo de vía & Km & Porcentaje \\
\hline Pavimentada & 4.788 & 29,9 \\
\hline Ripio & 6.313 & 39,4 \\
\hline Tierra & 4.928 & 30,7 \\
\hline Total & 16.029 & 100,0 \\
\hline
\end{tabular}

2. Se reporta la información de 2008 ya que el documento de referencia provee la estimación máxima de la extensión de la red vial fundamental. Otros documentos, también oficiales como el de la ABC (2017) o UDAPE (2015) reportan extensiones menores para años más recientes. A pesar de la incongruencia, lo que se pretende ilustrar es la perspectiva optimista de la $A B C$. 


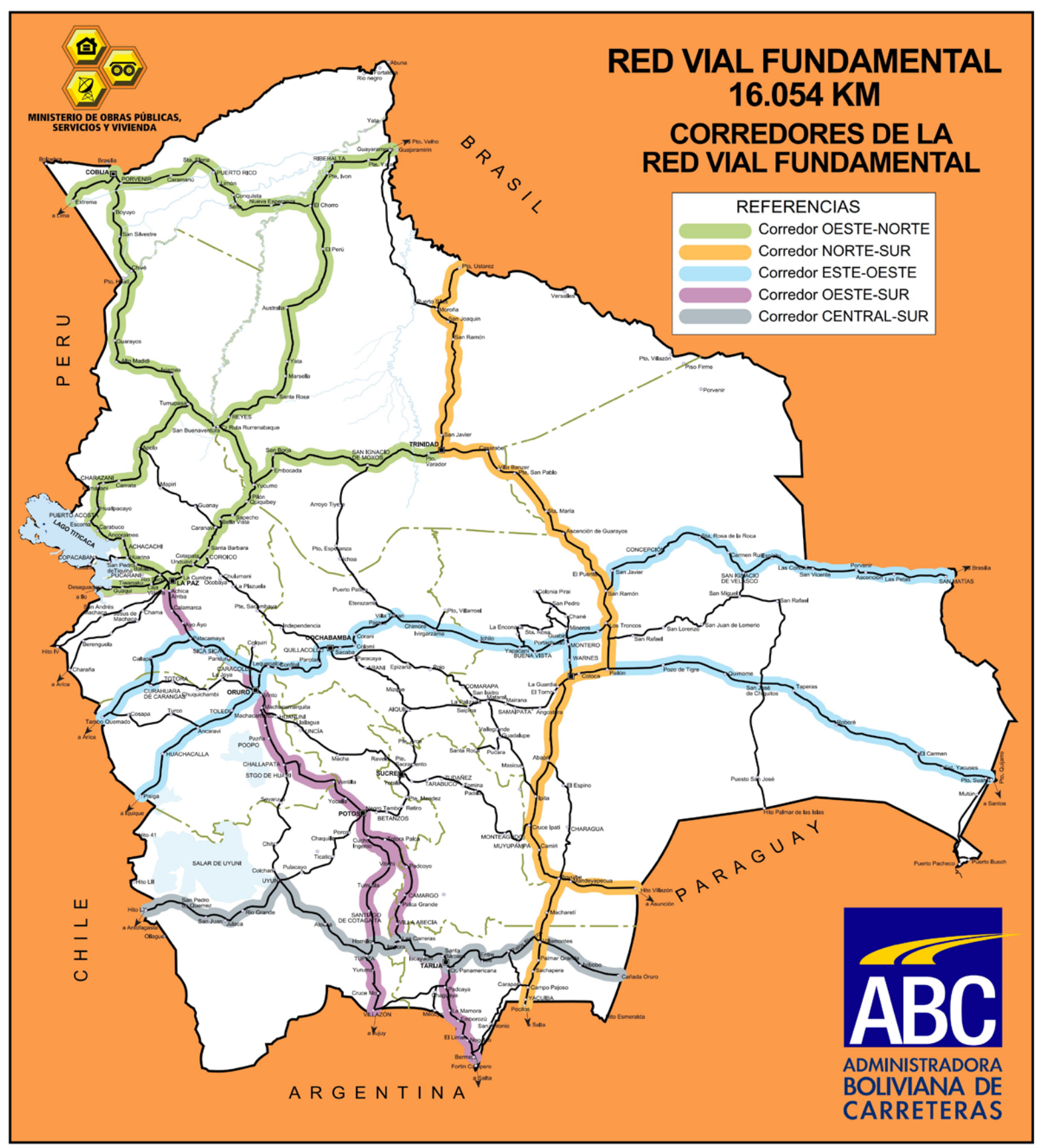

En lo que se refiere a su distribución según departamentos, puede verse que la red vial fundamental concentra un poco más de la mitad de su extensión en los tres departamentos que contienen el eje urbano nacional (La Paz - Cochabamba - Santa Cruz). En cierta medida, dicha concentración parece corresponder a la extensión de los departamentos: Santa Cruz que es el departamento más extenso concentra el $25 \%$ de la red mientras que Pando que es uno de los más pequeños tiene apenas el $3 \%$ (Cuadro 2).
Figura 1. Bolivia: Red Vial Fundamental y corredores de la red vial fundamental. Fuente: $A B C(2015)$ 
Cuadro 2. Bolivia - 2008, distribución de la red vial fundamental según departamentos. Fuente: Elaboración propia con datos de ABC (2008)

\begin{tabular}{|c|c|c|}
\hline Departamento & $\mathrm{Km}$ & Porcentaje \\
\hline La Paz & 2.746 & 17,1 \\
\hline Santa Cruz & 4.149 & 25,9 \\
\hline Beni & 2.060 & 12,9 \\
\hline Potosí & 1.783 & 11,1 \\
\hline Cochabamba & 1.293 & 8,1 \\
\hline Chuquisaca & 949 & 5,9 \\
\hline Oruro & 1.229 & 7,7 \\
\hline Tarija & 1.268 & 7,9 \\
\hline Pando & 552 & 3,4 \\
\hline Bolivia & 16.029 & 100,0 \\
\hline
\end{tabular}

\section{Las redes departamentales}

Si bien las redes viales departamentales se definían como: 1) las rutas que vinculan las capitales de provincia con la capital de cada departamento, directamente $\mathrm{o}$ a través de una ruta Fundamental y 2) las rutas que conectan con sistemas de transporte intermodal de importancia departamental (Servicio Departamental de Caminos, 1999: 26-27), actualmente y considerando la existencia de un contexto descentralizado y desconcentrado para la gestión pública ${ }^{3}$, la definición de la red departamental ha enfatizado en su rol de vinculación funcional (eficaz y eficiente) de flujos entre los niveles nacional y local. La extensión de la red departamental en 2012 se ha estimado en un poco más de $28 \mathrm{mil} \mathrm{km} \mathrm{(UDAPE,} \mathrm{2015).}$

\section{La redes locales - municipales}

Las redes locales pueden ser descritas -en el caso rural- como el conjunto de caminos vecinales y/o comunitarios que conectan pueblos y en general, localidades rurales entre sí y con las redes de mayor jerarquía. En el caso urbano, las redes comprenden un conjunto de vías con funciones y jerarquías específicas que conectan las diferentes zonas de la ciudad (avenidas, calles, pasajes, etc.). Por supuesto, en tanto más extendida y/o compleja sea una ciudad, su red vial tenderá a reflejar tanto el tamaño, la densidad y -en general- la complejidad de la ciudad. Así, cuanto más importante sea una ciudad, será más probable que ésta esté directamente conectada a la red fundamental. En total, en 2012, la extensión de la red municipal se ha estimado en algo más de $40 \mathrm{mil} \mathrm{km} \mathrm{(UDAPE,} \mathrm{2015).}$

El panorama general de la red vial en Bolivia podría resumirse destacando la tendencia generalizada a extenderse en longitud. Por supuesto los incrementos no han sido uniformes entre los tipos de redes. Así por ejemplo el Cuadro 3 muestra que el mayor incremento en términos absolutos corresponde a la extensión de la red departamental, misma que corresponde al 33\% del total de vías en el país. Por otro lado, se puede observar que la red municipal crece muy poco entre $2002 \mathrm{y}$ 2012 siendo que esta red representa el $41 \%$ del total de la infraestructura vial del país (Cuadro 3).
3. Según el cual existen tres grandes niveles: Nacional, Regional - Departamental y Local - Municipal, que cuentan con la autonomía y las capacidades de gestión consideradas como necesarias para asumir las correspondientes responsabilidades y promover el desarrollo en sus respectivos ámbitos territoriales. 
Cuadro 3. Bolivia, extensión de la red vial, por tipo de red, según superficie de rodadura, 2002 - 2012(p). Fuente: Elaboración propia, con información adaptada de UDAPE (2015: 28).

\begin{tabular}{|c|c|c|c|c|c|c|c|c|c|c|c|}
\hline $\begin{array}{l}\text { Red y Superficie } \\
\text { de rodadura }\end{array}$ & 2002 & 2003 & 2004 & 2005 & 2006 & 2007 & 2008 & 2009 & 2010 & 2011 & $2012(p)$ \\
\hline Total & 60.436 & 60.751 & 62.641 & 67.076 & 69.734 & 74.740 & 80.890 & 80.398 & 81.124 & 82.287 & 85.757 \\
\hline Pavimento & 4.003 & 4.291 & 4.599 & 4.637 & 4.831 & 5.088 & 6.379 & 7.961 & 8.495 & 9.521 & 10.018 \\
\hline Ripio & 18.302 & 18.514 & 19.406 & 22.857 & 23.913 & 29.910 & 30.145 & 28.700 & 31.865 & 31.367 & 31.767 \\
\hline Tierra & 38.131 & 37.946 & 38.636 & 39.582 & 40.990 & 39.742 & 44.366 & 43.737 & 40.764 & 41.399 & 43.972 \\
\hline Red Fundamental & 12.255 & 12.255 & 14.366 & 15.665 & 16.029 & 15.964 & 15.921 & 16.054 & 15.983 & 15.983 & 15.978 \\
\hline Pavimento & 3.790 & 4.032 & 4.276 & 4.394 & 4.514 & 4.741 & 5.910 & 7.443 & 7.859 & 8.009 & 8.232 \\
\hline Ripio & 4.980 & 4.738 & 5.603 & 5.843 & 6.455 & 7.837 & 5.570 & 4.755 & 7.382 & 7.232 & 7.004 \\
\hline Tierra & 3.485 & 3.485 & 4.487 & 5.428 & 5.060 & 3.386 & 4.441 & 3.856 & 742 & 742 & 742 \\
\hline Red Departamental & 11.531 & 14.224 & 14.606 & 16.433 & 17.851 & 19.284 & 24.532 & 24.524 & 24.157 & 25.299 & 28.773 \\
\hline Pavimento & 157 & 195 & 259 & 186 & 256 & 283 & 400 & 444 & 562 & 1.439 & 1.713 \\
\hline Ripio & 5.998 & 6.928 & 7.052 & 9.093 & 8.186 & 8.817 & 11.076 & 10.710 & 11.268 & 10.967 & 11.594 \\
\hline Tierra & 5.376 & 7.101 & 7.295 & 7.154 & 9.409 & 10.184 & 13.056 & 13.370 & 12.327 & 12.893 & 15.466 \\
\hline Red Municipal & 36.650 & 34.272 & 33.669 & 34.978 & 35.854 & 39.492 & 40.437 & 39.819 & 40.984 & 41.006 & 41.006 \\
\hline Pavimento & 56 & 64 & 64 & 57 & 61 & 64 & 69 & 74 & 74 & 74 & 74 \\
\hline Ripio & 7.324 & 6.848 & 6.751 & 7.921 & 9.272 & 13.256 & 13.499 & 13.236 & 13.215 & 13.168 & 13.168 \\
\hline Tierra & 29.270 & 27.360 & 26.854 & 27.000 & 26.521 & 26.172 & 26.869 & 26.510 & 27.695 & 27.764 & 27.764 \\
\hline
\end{tabular}

En lo que respecta a la densidad vial, mientras que el promedio mundial ha pasado lentamente de 23 a $28 \mathrm{~km}$ por cada $100 \mathrm{~km}^{2}$, entre 1990 y 2010, en el caso de Bolivia se ha estimado que la densidad vial se ha mantenido prácticamente constante (en 17 km) (Nina y Arduz, 2016:245).

Por lo expuesto, es posible destacar el significativo crecimiento (heterogéneo) de las redes viales en Bolivia y al mismo tiempo, los esfuerzos por mejorar la calidad de las vías, en particular, de las que conforman la red vial fundamental. Se trata de un crecimiento heterogéneo ya que el ritmo de extensión es variable según se trate de la red o del tipo de vía, incrementándose sobre todo la red fundamental y departamental en el tipo de vía pavimentada (Cuadro 3).

\section{Aspectos político-institucionales del sistema vial boliviano}

La extensión de las redes viales ha tenido lugar en determinadas condiciones político - institucionales que se describen sintéticamente, a continuación:

En el caso de la red vial fundamental y en el plano institucional, es preciso mencionar que a finales de 2006, fue creada la Administradora Boliviana de Carreteras (ABC), como una institución autárquica bajo tuición del Ministerio de Obras Públicas, la cual, básicamente, tomó a su cargo la gestión de la red vial fundamental. A través de la $\mathrm{ABC}$, el gobierno nacional ha desarrollado una clara política de provisión de infraestructura caminera, orientada específicamente no solamente a la extensión de la red vial fundamental sino también a su mejoramiento, es decir: ampliación de capacidad, mantenimiento, control, etc. (ABC, 2008).

En el caso de la red departamental, con algún grado de diversidad, existen en cada Gobierno Departamental, unidades específicamente encargadas de la gestión de la correspondiente red vial. Además, es importante destacar que en años recientes, se han establecido alianzas estratégicas entre los gobiernos departamentales y el gobierno nacional que permiten planificar y ejecutar proyectos de infraestructura vial de manera conjunta de tal 


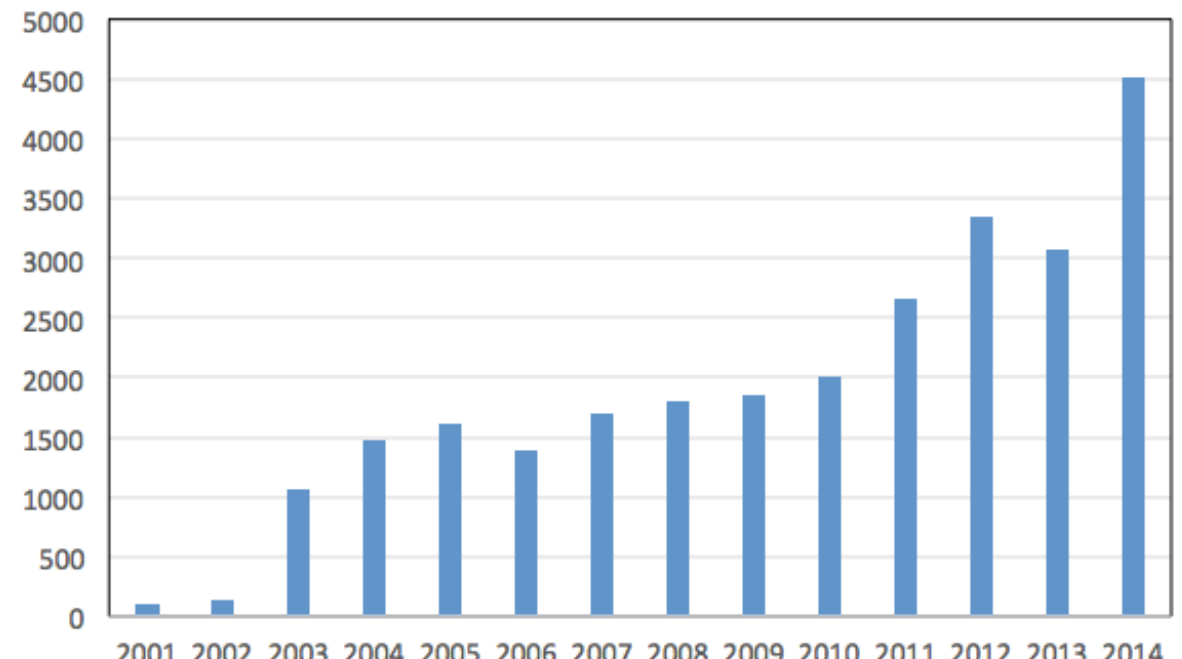

manera que se refuerza el carácter sistémico y la conectividad y funcionalidad de toda la red vial. Al igual que en el caso anterior, en el caso de las redes locales - municipales, en función de los recursos y otras capacidades de cada gobierno municipal, las respectivas unidades responsables de administrar las redes locales estarán más o menos fortalecidas y/o dispondrán de ciertas capacidades de gestión. En todo caso, también se han verificado iniciativas promovidas de manera conjunta con otros niveles de gobierno.

Considerando que el análisis de la política pública en los tres niveles de gobierno requeriría mayor detenimiento del que es posible en este documento, a continuación, el análisis se concentra en la política pública implementada en el caso de la red vial fundamental. En tal sentido, resulta bastante útil observar los niveles y la tendencia de la inversión pública en infraestructura carretera. Así, la información oficial (ABC, 2008) muestra que el presupuesto programado para el período 2007-2011 era de 2107 millones de dólares americanos y que éste se reduce en los tres siguientes quinquenios pero termina totalizando 5535 millones de USD previstos para el período 2007-2025, lo que representa sin duda una previsión de suma importancia.

En lo que respecta a la inversión en carreteras, la Figura 2 muestra los niveles y tendencias entre 2001 y 2014. Mientras que a principios de los años 2000, la inversión era bastante baja, ésta tiende a incrementarse significativamente desde 2010, llegando a ser en 2014 un poco más de 4.500 millones de bolivianos (Bolivia, 2015:43) lo cual representó aproximadamente el $2 \%$ del PIB (en Bs. Corrientes) y cerca del 14\% del total de la inversión pública en ese año. Todo esto refleja la enorme importancia asignada a la construcción de carreteras en años recientes.

El contexto político y el marco estratégico en que se ha planteado el referido programa de inversión tienen que ver con dos objetivos principales: 1) consolidar los corredores para la exportación de materias primas a los mercado globales en condiciones competitivas y 2) promover y fortalecer la vinculación de los mercados internos (regionales) en tanto se ha propuesto un modelo económico fuertemente basado en el consumo interno (Ministerio de Economía y Finanzas Públicas - Bolivia, 2011). Por tanto, el desarrollo de la infraestructura de caminos parece estar respondiendo antes que al incremento de la demanda de movilidad, a la acción de un conjunto de políticas públicas a nivel nacional y vinculado a modelos de desarrollo explícitamente propuestos por el gobierno nacional (Bolivia, 2015).

Sin embargo, si bien se ha reconocido la importancia de la inversión en infraestructura como una estrategia que complementa y que eventualmente sería capaz de
Figura 2. Bolivia: Inversión pública en carreteras 20012014 (millones de Bs.). Fuente: Elaboración propia, con datos del PDES (Bolivia, 2015: 43). 


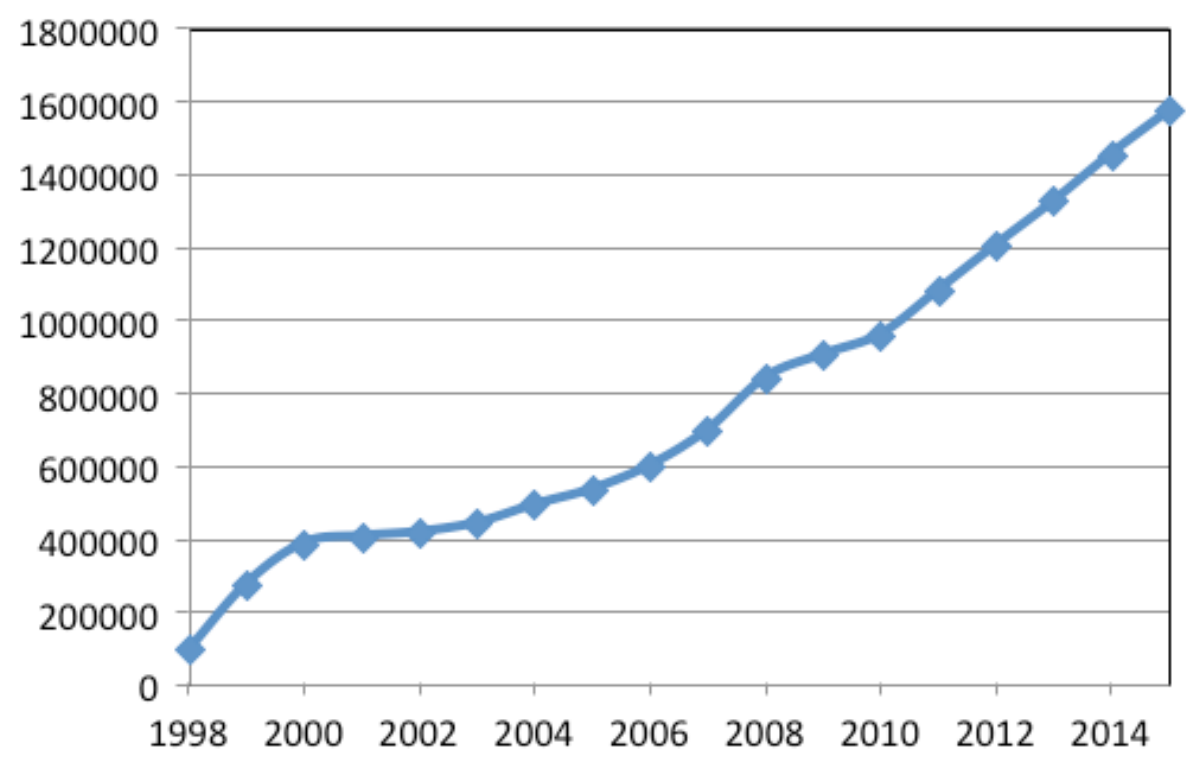

promover el desarrollo económico, tal como ya se ha sugerido, también se ha advertido la necesidad de mejorar los niveles de eficiencia de la inversión considerando la necesidad de realizar estudios integrales acerca de los impactos esperados de tales inversiones (Warner, 2014).

\section{¿Un automóvil para cada hogar?: La evolución de la "demanda"}

En esta sección se ofrece información oficial de tipo general acerca de los automóviles en Bolivia, es decir, la evolución y el tamaño del parque automotor así como los niveles de acceso (tenencia) al automóvil por parte de los hogares. Desde el punto de vista asumido, esta sección describe a los automóviles como si fuera el lado de la demanda, es decir, los automóviles "demandan" caminos. En ese sentido, la evolución del número de automóviles y otros aspectos relativos nos permiten conocer de una manera indirecta (y parcial) cuál ha sido la tendencia en la demanda de caminos a nivel nacional.

\section{Tamaño y crecimiento del parque automotor}

La Figura 3, utilizando información oficial (INE, 2016) muestra la evolución del parque automotor en Bolivia, entre 1998 y 2015, es decir, en el lapso de 18 años. Tal como se puede observar, el número de vehículos se ha incrementado significativamente en el período de referencia, pasando de un poco menos de 100 mil unidades a un poco más de un millón y medio en 2015. En el gráfico citado es posible distinguir dos períodos, el primero desde 1998 hasta el 2006 en el que el ritmo de crecimiento es moderado y el segundo desde 2006 hasta 2015 en el que el ritmo de crecimiento es mucho mayor.

Dado que se han identificado dos períodos con variaciones en el ritmo de crecimiento, la identificación de la trayectoria general resulta una tarea compleja. Por ejemplo, no resulta muy útil saber que el volumen total de 2015 es 16 veces el de 1998. Al analizar los incrementos anuales se ha observado que el valor promedio del incremento anual es de casi 87 mil vehículos; así, al suponer una tendencia lineal en el incremento del parque automotor, se obtiene una elevada correlación lineal $(\mathrm{R}=0.96)$. Sin embargo, la función lineal no es la más adecuada para explicar la tendencia en el largo plazo puesto que dicha función supone una expansión constante e ilimitada del parque automotor lo
Figura 3. Bolivia: Evolución del parque automotor 1998 - 2015 (total del número de vehículos). Fuente: Elaboración propia con datos del INE (2016). 
cual resulta poco plausible en el caso boliviano. En cualquier caso, es posible suponer que exista algún tipo de rasgo cíclico en la evolución del parque automotor que tenga fases de rápido crecimiento intercaladas con períodos de relativa estabilización o de lento crecimiento.

Cuadro 4a. Bolivia: Distribución relativa del parque automotor por departamentos, 1998-2006. Fuente: Elaboración propia con datos del INE (2016)

\begin{tabular}{|c|c|c|c|c|c|c|c|c|c|}
\hline Departamento & 1998 & 1999 & 2000 & 2001 & 2002 & 2003 & 2004 & 2005 & 2006 \\
\hline Chuquisaca & $5,1 \%$ & $4,8 \%$ & $4,5 \%$ & $4,4 \%$ & $4,4 \%$ & $4,3 \%$ & $4,3 \%$ & $4,1 \%$ & $4,1 \%$ \\
\hline La Paz & $44,4 \%$ & $34,1 \%$ & $30,3 \%$ & $29,9 \%$ & $29,7 \%$ & $29,5 \%$ & $28,6 \%$ & $28,4 \%$ & $28,4 \%$ \\
\hline Cochabamba & $20,8 \%$ & $23,4 \%$ & $21,6 \%$ & $21,5 \%$ & $21,5 \%$ & $21,5 \%$ & $21,9 \%$ & $22,6 \%$ & $23,8 \%$ \\
\hline Oruro & $4,0 \%$ & $5,3 \%$ & $5,1 \%$ & $5,1 \%$ & $5,1 \%$ & $5,2 \%$ & $5,5 \%$ & $5,5 \%$ & $5,7 \%$ \\
\hline Potosí & $2,8 \%$ & $4,3 \%$ & $4,1 \%$ & $4,0 \%$ & $4,0 \%$ & $3,9 \%$ & $4,0 \%$ & $3,8 \%$ & $3,9 \%$ \\
\hline Tarija & $5,5 \%$ & $5,8 \%$ & $5,9 \%$ & $5,9 \%$ & $5,8 \%$ & $5,7 \%$ & $5,5 \%$ & $5,3 \%$ & $5,3 \%$ \\
\hline Santa Cruz & $16,8 \%$ & $21,8 \%$ & $27,6 \%$ & $28,1 \%$ & $28,4 \%$ & $28,7 \%$ & $29,0 \%$ & $28,9 \%$ & $27,6 \%$ \\
\hline Beni & $0,5 \%$ & $0,6 \%$ & $0,9 \%$ & $1,0 \%$ & $1,1 \%$ & $1,2 \%$ & $1,3 \%$ & $1,3 \%$ & $1,3 \%$ \\
\hline Pando & $0,0 \%$ & $0,0 \%$ & $0,0 \%$ & $0,0 \%$ & $0,0 \%$ & $0,0 \%$ & $0,0 \%$ & $0,0 \%$ & $0,0 \%$ \\
\hline Total & $100,0 \%$ & $100,0 \%$ & $100,0 \%$ & $100,0 \%$ & $100,0 \%$ & $100,0 \%$ & $100,0 \%$ & $100,0 \%$ & $100,0 \%$ \\
\hline
\end{tabular}

Cuadro 4b. Bolivia: Distribución relativa del parque automotor por departamentos, 2007-2015. Fuente: Elaboración propia con datos del INE (2016)

\begin{tabular}{|c|c|c|c|c|c|c|c|c|c|}
\hline Departamento & 2007 & 2008 & 2009 & 2010 & 2011 & 2012 & 2013 & 2014 & 2015 \\
\hline Chuquisaca & $4,0 \%$ & $3,9 \%$ & $4,0 \%$ & $4,0 \%$ & $4,0 \%$ & $3,9 \%$ & $4,0 \%$ & $3,9 \%$ & $4,0 \%$ \\
\hline La Paz & $27,4 \%$ & $26,6 \%$ & $26,0 \%$ & $25,9 \%$ & $25,4 \%$ & $25,1 \%$ & $25,0 \%$ & $24,6 \%$ & $24,2 \%$ \\
\hline Cochabamba & $23,4 \%$ & $23,5 \%$ & $23,5 \%$ & $23,3 \%$ & $23,4 \%$ & $22,8 \%$ & $22,3 \%$ & $21,9 \%$ & $21,6 \%$ \\
\hline Oruro & $5,8 \%$ & $6,0 \%$ & $6,0 \%$ & $5,9 \%$ & $6,0 \%$ & $5,9 \%$ & $5,8 \%$ & $5,7 \%$ & $5,5 \%$ \\
\hline Potosí & $4,0 \%$ & $3,7 \%$ & $3,6 \%$ & $3,6 \%$ & $4,0 \%$ & $3,9 \%$ & $3,8 \%$ & $3,7 \%$ & $3,6 \%$ \\
\hline Tarija & $5,4 \%$ & $5,2 \%$ & $5,4 \%$ & $5,6 \%$ & $5,5 \%$ & $5,4 \%$ & $5,4 \%$ & $5,5 \%$ & $5,5 \%$ \\
\hline Santa Cruz & $28,9 \%$ & $29,9 \%$ & $30,2 \%$ & $30,5 \%$ & $30,3 \%$ & $31,1 \%$ & $31,6 \%$ & $32,3 \%$ & $33,0 \%$ \\
\hline Beni & $1,3 \%$ & $1,2 \%$ & $1,3 \%$ & $1,4 \%$ & $1,5 \%$ & $1,8 \%$ & $2,0 \%$ & $2,2 \%$ & $2,3 \%$ \\
\hline Pando & $0,0 \%$ & $0,0 \%$ & $0,0 \%$ & $0,0 \%$ & $0,0 \%$ & $0,1 \%$ & $0,1 \%$ & $0,2 \%$ & $0,2 \%$ \\
\hline Total & $100,0 \%$ & $100,0 \%$ & $100,0 \%$ & $100,0 \%$ & $100,0 \%$ & $100,0 \%$ & $100,0 \%$ & $100,0 \%$ & $100,0 \%$ \\
\hline
\end{tabular}

En cuanto a la distribución del parque automotor por departamentos (Cuadros 4a y $4 b$ ), es importante notar que en el período de referencia los tres departamentos cuyas capitales conforman el eje urbano nacional (La Paz, Cochabamba y Santa Cruz), concentran una gran mayoría del parque automotor, representando en conjunto entre el 82 y el 78 por ciento del total de vehículos en 1998 y en 2015 respectivamente. Al inicio del período estudiado, La Paz es el departamento que más vehículos tiene (44\%), seguido de Cochabamba (20\%) y Santa Cruz (16\%), sin embargo, al final del período de referencia (2015), es el departamento de Santa Cruz el que más vehículos tiene (33\%) seguido de La Paz (24\%) y Cochabamba (21\%). Este cambio parece reflejar la jerarquía de los respectivos centros urbanos vista en términos del tamaño poblacional. También es importante notar en el Cuadro 4, que Beni y Pando son departamentos con mínimos volúmenes de vehículos, los cuales -a pesar de incrementarse- continúan siendo pequeños en comparación con el resto de los departamentos. 


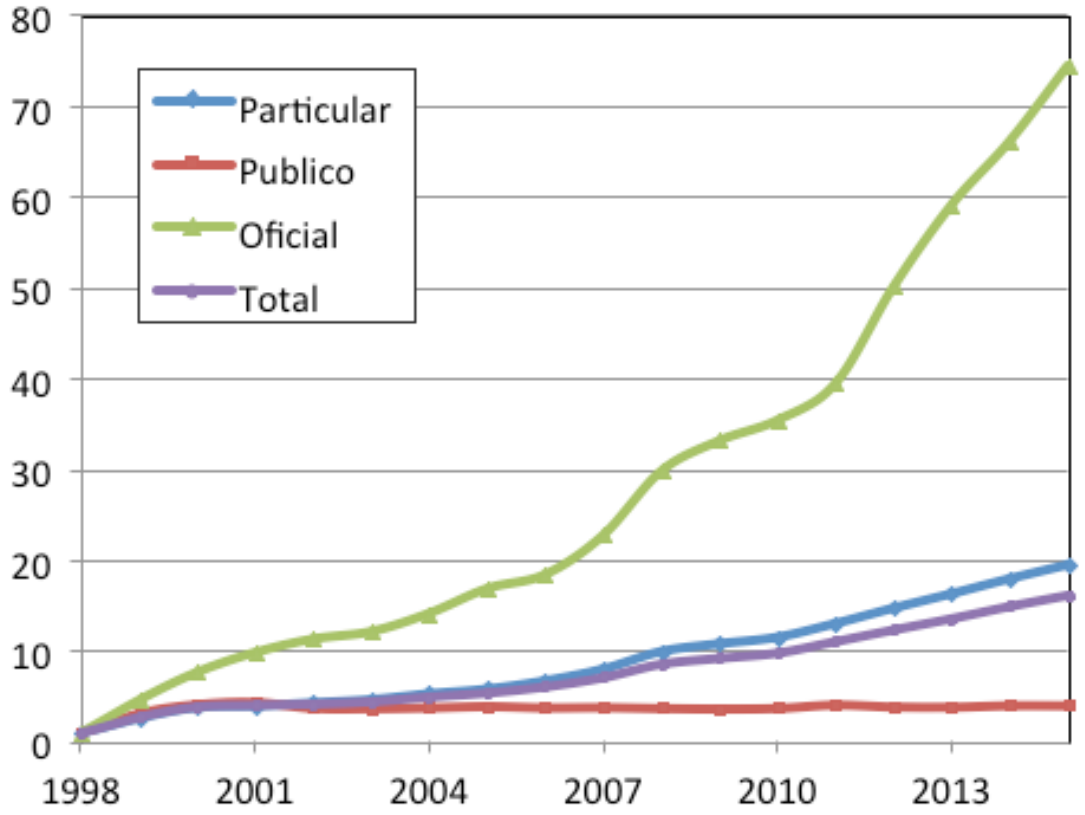

Teniendo en cuenta el tipo de vehículo ${ }^{4}$, es posible ver en la Figura 4 que el ritmo de crecimiento no ha sido el mismo para todos. Mientras el grupo de vehículos oficiales experimenta un crecimiento acelerado, los vehículos públicos crecen modestamente. Así, al final del período de referencia, el tipo oficial se ha multiplicado por 74 veces $^{5}$, pero como este grupo representa una ínfima parte del total, su efecto incremental no se refleja en el total. Por su parte, el grupo de los públicos se ha multiplicado apenas por 4. La distribución del parque automotor en función del tipo de vehículo muestra una importante concentración en el grupo de los particulares la misma que tiende a incrementarse siendo 76\% en 1998 y pasa a representar el 92\% en 2015.

El segundo grupo en importancia es el de los públicos que pasan de representar el $23 \%$ en 1998 a ser un poco menos del 6\% en 2015. Aunque la participación de los vehículos oficiales es mínima en 1998 (0,4\%) ésta se incrementa significativamente, y llega a ser casi el 2\% en 2015 (INE, 2016). Las diferencias en los ritmos de crecimiento según el tipo de vehículo sugieren como tendencia general el creciente predominio del automóvil para uso particular.

Hasta aquí se ha podido observar que existe una tendencia creciente en el número de vehículos en Bolivia. Que la mayoría de ellos son de tipo particular y se concentran en los departamentos del eje urbano nacional. A continuación, se completa el panorama de la demanda de caminos incluyendo información general acerca de la proporción de hogares bolivianos que según los censos de 2001 y 2012, poseen un vehículo automotor.

\section{Niveles de tenencia de automóviles en 2001 y 2012}

De acuerdo con la información censal, en 2001, de los casi 2 millones de hogares particulares ${ }^{6}$ bolivianos, un poco más de un cuarto de millón tenía al menos un automóvil en $2001^{7}$ y éstos representaban un $12 \%$ del total de hogares. En 2012, los hogares particulares son casi 3 millones, de los cuales, un poco más de seiscientos mil hogares tienen automóvil, esto equivale al 22\% (Cuadro 5). Más allá de que el incremento en la proporción de hogares con automóvil sea significativo (9\%), es importante tomar en cuenta que desde ciertos puntos de vista, se esperaba que existiera ese incremento. Así por ejemplo,
Figura 4. Bolivia: Evolución relativa del parque automotor, por tipo de servicio (Índices simples, año base: $1998=1$ ). Fuente: Elaboración propia con datos del INE (2016)

4. El Tipo de Vehículo incluye las categorías: Particular, Público y Oficial, mismas son asignadas de acuerdo a ciertos criterios administrativos; los automóviles particulares son de uso privado de sus propietarios y éstos no pueden prestar servicios remunerados de transporte al público en general, los automóviles públicos son usados por sus propietarios para prestar algún servicio de transporte comercial (ya sea de carga o de pasajeros, local, nacional o internacional) y finalmente, los vehículos oficiales son aquellos que han sido adquiridos por alguna repartición del estado (gobiernos locales, departamentales o nacional) y se usan en actividades oficiales y/o de la función pública. Empero, estas categorías no llegan a reflejar el hecho de que en la práctica, por ejemplo, muchos vehículos particulares son utilizados como vehículos públicos.

5. De alguna manera, este incremento parecería estar reflejando una suerte de creciente protagonismo del Estado y/o un claro interés en una mayor movilidad de los funcionarios públicos entre otros.

6. La información reportada respecto de los hogares corresponde a los hogares particulares que estaban presentes en sus respectivas viviendas al momento del censo. Esta precisión se la hace porque solamente a esos hogares se les preguntó acerca de la tenencia de automóvil.

7. Es importante notar que la pregunta respectiva tan solo identifica al hogar que posee un automóvil, no es posible distinguir los casos en los que un hogar posee más de un automóvil. Además, en tanto la pregunta se aplica a hogares particulares con ocupantes presentes, tampoco se puede aproximar el volumen del parque automotor correspondiente a empresas públicas, privadas, instituciones, etc. 
desde la perspectiva de la teoría de la transición de la movilidad (Zelinsky, 1971), se esperaba y aún se espera que una sociedad como la boliviana experimente crecientes niveles de movilidad y el hecho de que más hogares posean más automóviles es en cierta medida un reflejo de esa "transición" hacia una mayor movilidad.

El Cuadro 5 también muestra el porcentaje de hogares que tienen un automóvil, por departamento. Al respecto, es posible ver que el departamento de Santa Cruz es el que en 2001 tiene una mayor proporción de hogares con automóvil (18\%) seguido de cerca por Tarija (17\%) y Cochabamba (15\%); más atrás está La Paz (9\%). En último lugar se encuentran Potosí y Beni, con 7\% y 6\% respectivamente. En 2012, siguen en el mismo orden los tres departamentos ya nombrados en 2001 y los últimos lugares ahora los ocupan Beni y Pando, los cuales -durante el período intercensal- han registrado los menores incrementos (en puntos porcentuales). En todo caso, llama mucho la atención el caso de Oruro, cuya proporción es la que más se incrementa en el período de estudio (11 puntos porcentuales) (Cuadro 5).

Al considerar en el análisis las diferencias según área geográfica, el Cuadro 6 muestra los porcentajes de hogares con automóvil para el área rural y para el área urbana ${ }^{8}$. A nivel nacional, el porcentaje de hogares rurales con automóvil es de $4 \%$ en 2001 y éste pasa a ser de $12 \%$ en 2012. Como era de esperarse, dichos porcentajes en el caso del área rural son claramente más bajos que el nivel general y -por supuesto- mucho menores que los niveles calculados para el área urbana, tanto a nivel nacional como en cada uno de los departamentos. Así, el porcentaje de hogares urbanos con automóvil para todo el país es de 18\% en 2001 y se incrementa a 27\% en 2012.

Cuadro 5. Bolivia, Número de hogares particulares, con automóvil, por departamentos, 2001 y 2012. Fuente: Elaboración propia, usando REDATAM, con datos de los CNPV (INE, 2001 y 2012).
8. Según la definición del Instituto Nacional de Estadística (INE), se define como urbana toda comunidad con 2000 o más habitantes.

\begin{tabular}{|c|c|c|c|c|c|c|c|}
\hline \multirow[t]{2}{*}{ Departamento } & \multicolumn{3}{|c|}{ Hogares en 2001} & \multicolumn{3}{|c|}{ Hogares en 2012} & \multirow{2}{*}{$\begin{array}{l}\text { Diferencia } \\
\text { Puntos } \\
\text { porcentuales }\end{array}$} \\
\hline & Total & $\begin{array}{l}\text { Con } \\
\text { automóvil }\end{array}$ & Porcentaje & Total & $\begin{array}{l}\text { Con } \\
\text { automóvil }\end{array}$ & Porcentaje & \\
\hline Chuquisaca & 118.918 & 11.601 & 9,8 & 148.417 & 26.470 & 17,8 & 8,1 \\
\hline La Paz & 630.072 & 61.682 & 9,8 & 846.507 & 163.520 & 19,3 & 9,5 \\
\hline Cochabamba & 352.411 & 54.148 & 15,4 & 510.924 & 128.901 & 25,2 & 9,9 \\
\hline Oruro & 104.123 & 11.224 & 10,8 & 149.788 & 33.143 & 22,1 & 11,3 \\
\hline Potosí & 180.323 & 12.591 & 7,0 & 239.492 & 36.245 & 15,1 & 8,2 \\
\hline Tarija & 87.157 & 15.016 & 17,2 & 125.415 & 33.339 & 26,6 & 9,4 \\
\hline Santa Cruz & 428.653 & 78.943 & 18,4 & 640.022 & 177.693 & 27,8 & 9,3 \\
\hline Beni & 65.481 & 4.198 & 6,4 & 93.027 & 9.665 & 10,4 & 4,0 \\
\hline Pando & 10.527 & 895 & 8,5 & 25.105 & 3.152 & 12,6 & 4,1 \\
\hline BOLIVIA & 1.977 .665 & 250.298 & 12,7 & 2.778 .697 & 612.128 & 22,0 & 9,4 \\
\hline
\end{tabular}


Cuadro 6. Bolivia, Grado de Urbanización y porcentaje de hogares con automóvil, por área geográfica, según departamentos, 2001 y 2012. * GU = Grado de Urbanización (calculado a través del cociente de la población urbana entre la población total, expresado en porcentaje). Fuente: Elaboración propia, usando REDATAM, con datos de los CNPV, (INE, 2001 y 2012).

\begin{tabular}{|c|c|c|c|c|c|c|}
\hline \multirow[t]{2}{*}{ Departamento } & \multicolumn{2}{|l|}{ GU* } & \multicolumn{2}{|c|}{ Área rural } & \multicolumn{2}{|c|}{ Área urbana } \\
\hline & 2001 & 2012 & 2001 & 2012 & 2001 & 2012 \\
\hline Chuquisaca & $41 \%$ & $49 \%$ & $2,6 \%$ & $8,0 \%$ & $19,4 \%$ & $27,8 \%$ \\
\hline La Paz & $66 \%$ & $67 \%$ & $2,4 \%$ & $11,5 \%$ & $14,1 \%$ & $23,7 \%$ \\
\hline Cochabamba & $59 \%$ & $68 \%$ & $5,5 \%$ & $14,1 \%$ & $22,8 \%$ & $31,5 \%$ \\
\hline Oruro & $60 \%$ & $64 \%$ & $4,8 \%$ & $15,3 \%$ & $15,4 \%$ & $26,6 \%$ \\
\hline Potosí & $34 \%$ & $41 \%$ & $3,2 \%$ & $9,2 \%$ & $14,8 \%$ & $24,6 \%$ \\
\hline Tarija & $63 \%$ & $65 \%$ & $8,6 \%$ & $19,2 \%$ & $21,7 \%$ & $30,6 \%$ \\
\hline Santa Cruz & $76 \%$ & $81 \%$ & $8,1 \%$ & $16,2 \%$ & $21,3 \%$ & $30,3 \%$ \\
\hline Beni & $69 \%$ & $73 \%$ & $2,2 \%$ & $5,9 \%$ & $8,2 \%$ & $12,0 \%$ \\
\hline Pando & $40 \%$ & $49 \%$ & $3,6 \%$ & $6,3 \%$ & $14,9 \%$ & $18,0 \%$ \\
\hline BOLIVIA & $62 \%$ & $67 \%$ & $4,2 \%$ & $12,3 \%$ & $18,0 \%$ & $27,2 \%$ \\
\hline
\end{tabular}

Cuadro 7. Bolivia, tasas de crecimiento del porcentaje de hogares con automóvil y estimación de hogares con automóvil para 2016. * r: Tasas promedio de crecimiento anual intercensal 2001-2012. Fuente: Elaboración propia, usando REDATAM, con datos de los CNPV, (INE, 2001 y 2012).

\begin{tabular}{|l|l|l|}
\hline Departamento & $\mathrm{r}^{*}$ & $\mathbf{2 0 1 6}$ \\
\hline Chuquisaca & 5,4 & $23 \%$ \\
\hline La Paz & 6,0 & $26 \%$ \\
\hline Cochabamba & 4,4 & $32 \%$ \\
\hline Oruro & 6,4 & $31 \%$ \\
\hline Potosí & 6,9 & $21 \%$ \\
\hline Tarija & 3,9 & $32 \%$ \\
\hline Santa Cruz & 3,6 & $33 \%$ \\
\hline Beni & 4,3 & $13 \%$ \\
\hline Pando & 3,5 & $15 \%$ \\
\hline BOLIVIA & 4,9 & $28 \%$ \\
\hline
\end{tabular}

Entre otras cosas, es posible observar que el Grado de Urbanización de cada departamento no parece tener ninguna asociación con los porcentajes calculados ya sea a nivel rural o a nivel urbano. Por otro lado, si bien han existido incrementos importantes entre cada momento censal, éstos son relativamente similares entre áreas geográficas, siendo el departamento de Oruro el caso en el que se verificaron los mayores incrementos (11 puntos porcentuales) y el Beni corresponde a los mínimos incrementos (3 puntos porcentuales) (Cuadro 6).

De acuerdo con la información censal analizada, es posible verificar la existencia de importantes incrementos en la proporción de hogares con automóviles y por lo mismo, es posible suponer que existe una tendencia general creciente. El Cuadro 7 muestra que la tasa de crecimiento de la proporción de hogares con automóvil ha sido calculada en $4,9 \%$ para el país. Dado que se trata de un proceso complejo, en realidad no existen muchos elementos que permitan suponer la tendencia secular ni tampoco estimar su 
variabilidad. Consecuentemente, en el corto y mediano plazo -sobre todo- podrían verificarse cambios drásticos y al mismo tiempo podría suceder que las tendencias obedezcan más bien a dinámicas más locales - departamentales. En tal sentido el Cuadro 7 no solamente muestra la estimación del porcentaje de hogares con automóvil a nivel nacional para el año 2016 (28\%) sino también ofrece estimaciones a nivel departamental sobre la base de las tasas calculadas en cada caso. Así, uno de los posibles escenarios implicaría un proceso de "convergencia" entre un importante grupo de departamentos que ya tenían niveles relativamente elevados de tenencia de automóvil.

Tal como se ha podido ver en esta sección, existe una clara tendencia no solamente de incremento del parque automotor sino también en la tenencia y/o acceso al automóvil por parte de los hogares. Estas tendencias lógicamente se reflejan en mayores demandas de caminos.

\section{Correspondencias entre la provisión de caminos y el acceso a los automóviles}

Tomando en cuenta tanto el análisis de la oferta como el de la demanda de movilidad, en los cuales se ha podido verificar claramente la existencia de tendencias incrementales en el pasado reciente, es posible destacar lo siguiente:

Existe una enorme correspondencia en los incrementos de caminos y automóviles tanto en el tiempo como en su distribución regional, es decir, en los departamentos que conforman el eje urbano nacional y en las zonas urbanas.

Estas tendencias coinciden además con lo previsto por el modelo de la transición de la movilidad de Zelinsky que distingue en una de sus fases la creciente importancia de ciertos centros urbanos o polos alrededor de los cuales se organizan los flujos, siendo éstos polos de dos tipos: a) internos, representados por los tres principales centros urbanos que conforman el eje urbano nacional y b) externos, representados por los puertos de exportación a los que se pretende alcanzar a través de los corredores bioceánicos. Al respecto, la creciente demanda de acceso al automóvil también confirma las previsiones del modelo de Zelinsky.

Sin embargo, es preciso notar que no es posible afirmar la plena correspondencia entre los enormes esfuerzos por extender y mejorar la red vial fundamental y el hecho de que los principales incrementos del parque automotor corresponden a los vehículos particulares. Así, bajo el supuesto de que los vehículos particulares son utilizados principalmente para la movilidad local es decir, usando la red local - municipal y que esta red es la que menos ha crecido en el período de estudio, pareciera existir una contradicción según la cual, se está desarrollando una "cultura del automóvil" que se expresa por medio de una creciente demanda de movilidad, pero son más bien las redes fundamental y secundaria las que crecen.

Para comprender esta situación, es importante considerar también que la interacción entre la construcción y/o mejoramiento de las carreteras nacionales con los procesos de expansión urbana, ha contribuido a consolidar procesos de urbanización en las cercanías de dichas carreteras (Rocha, 2010) y la creciente demanda de vías ha hecho que las redes: fundamental y departamentales, sean utilizadas intensivamente por el tráfico local. En efecto, considerando por un lado que uno de los componentes más importantes de la política de mejoramiento de la red fundamental ha consistido en la construcción de las "dobles vías"9 en el eje carretero nacional (ABC, 2014) y por otro lado, considerando que los procesos de expansión urbana han tomado como ejes
9. Entre La Paz y Oruro, Oruro y Cochabamba y entre Cochabamba y Santa Cruz, en éste último caso, también se encuentra en construcción una doble vía en un importante tramo de la carretera antigua. 
estructurantes a las vías fundamentales (Rocha, 2010) a partir de las cuales se han ido consolidando las redes viales locales de una manera prácticamente inercial, es posible comprender que, consecuentemente, se han consolidado progresivamente patrones de uso ineficiente, asociados a problemas tales como la congestión vehicular, precariedad, vulnerabilidad, etc. Por supuesto, aún no existen estudios específicos al respecto, sin embargo, es posible observar que la correspondencia entre el incremento de caminos y el incremento de los automóviles implica ciertas dinámicas socio-territoriales contradictorias.

En todo caso, es importante notar que el Estado ha jugado un papel clave en la configuración de las tendencias observadas en la red vial fundamental, a través de la política pública y a través de la inversión de enormes cantidades de recursos económicos.

Aunque es posible esperar efectos positivos de esta política, los resultados concretos no pueden ser rastreados tan fácilmente como se quisiera y al mismo tiempo, será preciso tener en cuenta que se han producido y se producirán otros efectos indirectos y/o secundarios, uno de los cuales tiene que ver con la creciente demanda de acceso a los automóviles y las consecuentes transformaciones en los patrones de movilidad espacial de los grupos que conforman la sociedad boliviana. Ello requerirá evaluar con especial atención los cambios en los ámbitos económicos, culturales, sociales, etc.

Tal como se ha podido ver a lo largo de este documento, a pesar de la aparente correspondencia en la evolución y las tendencias de automóviles, caminos e inversión en caminos, en Bolivia en el pasado reciente, también es posible ver que existe cierta complejidad implícita que -entre otras cosas- tiene que ver con los efectos directos e indirectos, inmediatos y diferidos de una política pública consistentemente enfocada en el desarrollo de infraestructura vial. En tal sentido, vale la pena notar -por un ladoque los efectos inmediatos de dicha política parecen reflejarse en incentivos al uso del automóvil y consecuente saturación de las redes viales locales lo cual podría derivar y/o profundizar ciertas problemáticas urbanas. Así, si bien existe una cierta dinamización de la economía y una ilusión de mayor movilidad, también existen crecientes ineficiencias y mayores desigualdades sociales.

Por otro lado, si bien se espera que las consecuencias a mediano y largo de la política caminera sean positivas y logren integrar no solamente las economías de la sub-región sino también las economías regionales, ésta integración también dependerá de otras políticas complementarias que promuevan sectores estratégicos de la economía nacional. Los caminos no pueden ni deben ser considerados como soluciones mágicas a los problemas estructurales de una economía tan limitada como la de Bolivia. Por tanto, es imperioso que el gobierno procure estar listo para transformar los cambios de la infraestructura de caminos en verdaderos impulsos para el desarrollo económico y social en Bolivia. 


\section{Q Bibliografía}

» ADMINISTRADORA BOLIVIANA DE CARRETERAS - ABC (2008) Presentación de la Dirección de la Administradora Boliviana de Carreteras, La Paz: ABC, disponible en: http://dircaibea.org/sites/all/themes/dircaibea/images/ presboliviapresendir_08.pdf, último acceso: 5 de Julio de 2017.

» ADMINISTRADORA BOLIVIANA DE CARRETERAS - ABC (2014) Informe de gestión 2014, La Paz: ABC, disponible en: http://www.abc.gob.bo/sites/default/ files/informe_de_gestion_2014_final-2.pdf, último acceso: 5 de Julio de 2017.

» ADMINISTRADORA BOLIVIANA DE CARRETERAS - ABC (2015) Red Vial Fundamental - 2015, La Paz: ABC, disponible en: http://www.abc.gob.bo/sites/ default/files/corredores_abc-rvf.pdf, último acceso: 5 de julio de 2017.

» ADMINISTRADORA BOLIVIANA DE CARRETERAS - ABC (2017) Red Vial Fundamental - 2017, La Paz: ABC.

» BANCO MUNDIAL (1987) Transportes urbanos, Washington DC: The World Bank Group.

»BOLIVIA, ESTADO PLURINACIONAL DE (2011) Ley no 165. Ley General de Transporte. La Paz: Gaceta Oficial de Bolivia.

» BOLIVIA, ESTADO PLURINACIONAL DE (2015) Plan de Desarrollo Económico y Social 2016-2020. En el marco del Desarrollo Integral para Vivir Bien. La Paz: Ministerio de Planificación

»BOWLES, Paul (2004) Globalisation and Neoliberalism: A Taxonomy and Some Implications for 'Anti-Globalisation', Inaugural Surendra Patel Lecture in International Development Studies at Saint Mary's University, Halifax-NS, November 19, 2004.

»BROWN, Jeffrey, MORRIS, Eric, TAYLOR, Brian (2009) Planning for Cars in Cities. Planners, Engineers, and Freeways in the 2oth Century, Journal of the American Planning Association, Vol. 75, No 2, Spring 2009, pp. 161-177.

»BROWNE, Enrique (1972) La eficiencia de la ineficiencia, revista EURE No 5, Santiago de Chile: PUC.

» BUTLER, Joseph (1994) Geografía Económica, México: LIMUSA.

»CENTRO LATINOAMERICANO DE DEMOGRAFÍA - CELADE (1996) Impacto de las Tendencias Demográficas sobre los Sectores Sociales de América Latina, Santiago de Chile: CELADE - CEPAL.

" CYPHER, James; DIETZ, James (2004) The Process of Economic Development (2nd Ed.). New York: Routledge.

» GERMANI, Gino (1962) La movilidad social en la Argentina. En S. M. Lipset \& R. Bendix (Eds.), Movilidad social en la sociedad industrial. Buenos Aires: EUDEBA.

" GRAY MOLINA, George (2004) Desigualdad en Bolivia. La Paz: UDAPE

» INSTITUTO NACIONAL DE ESTADíSTICA - INE (2001) Censo Nacional de Población y Vivienda 2001, Base de datos en formato REDATAM.

» INSTITUTO NACIONAL DE ESTADÍSTICA - INE (2012) Censo Nacional de Población y Vivienda 2012, Base de datos en formato REDATAM. 
» INSTITUTO NACIONAL DE ESTADÍSTICA - INE (2016) Estadísticas del Parque Automotor, La Paz: INE.

" ITURRALDE, Pablo; FRANCKE, Pedro (2013) Modelo primario-exportador en América Latina: balances, retos y alternativas desde la economía. Cuadernos de Debate No 3, Lima: Red Latinoamericana sobre las Industrias Extractivas - RLIE - ALOP, disponible en: http://redextractivas.org/wp-content/uploads/2016/o8/ Cuadernos-de-Debate-N3.pdf, último acceso: 5 de Julio de 2017.

»LASERNA, Roberto (Coord.) (2012) Estatismo y liberalismo. Experiencias en desarrollo. La Paz: Fundación Milenio.

»LAVAYÉN, Jimena; VEIZAGA, Jorge (2004) Redes y flujos de tráfico y transporte inter municipios en Cochabamba: implicaciones en la organización económica espacial de las actividades (Bases para una aproximación al estudio de los sistemas urbanos). En F. Bustamante Mercado (Ed.), Planificación y Municipalización en Bolivia. Cochabamba: PROMEC-UMSS.

" MINISTERIO DE ECONOMÍA Y FINANZAS PÚBLICAS - Bolivia (2015) El nuevo modelo económico, social, comunitario y productivo, Economía Plural, Año 1, Número 1. Disponible online: http://medios.economiayfinanzas.gob.bo/MH/ documentos/Materiales_UCS/Revistas/Revista_01.pdf, último acceso: 5 de Julio de 2017.

"NINA, Osvaldo; ARDUZ, Mario (2016) Vías camineras, En: Andersen, et al (Eds.) El ABC del desarrollo en Bolivia, La Paz: INESAD, pp. 243-252.

» NOGALES, Beatriz (1985) El Transporte en la Región de Cochabamba, en Transportes y Servicios Urbanos en América Latina, Trabajo presentado en Seminario - Taller INRETS/CIUDAD, Quito Ecuador, 1985.

» PARPART, Jane; VELTMEYER, Henry (2003) The Dynamics of Development Theory and Practice: A Review of its Shifting Dynamics. Canadian Journal of Development Studies, 25 (1).

» PETRAS, James; VELTMEYER, Henry (2000) Globalisation or Imperialism? Cambridge Review of International Affairs, Autumn-Winter, Vol. XIV, No. 1, 2000.

» RODE, Philipp; FLOATER, Graham (2014) Accessibility in Cities: Transport and Urban Form, The New Climate Economy NCE - Cities, Paper 03, November 2014. London School of Economics and Political Science.

»ROCHA, Fidel (2010) La Zona Metropolitana de Cochabamba, Bolivia: crecimiento y expansión urbana precaria, Tesis de Maestría en Población y Desarrollo, Tesis de Maestría en Población y Desarrollo, México: FLACSO.

» SALERNO, Bruno (2012) Un viaje por la movilidad cotidiana. El espacio entre el transporte y el individuo. Perspectiva Geográfica, Vol. 17, Enero-Diciembre 2012, pp. 213-232.

" SERVICIO DEPARTAMENTAL DE CAMINOS - SDC (1999) Plan Operativo Anual, Cochabamba: SDC.

»SHARP, Richard (2005) Resultados de la privatización de ferrocarriles en América Latina, Transport Papers TP-6, September 2005. The World Bank: Washington D.C. Disponible en: http://siteresources.worldbank.org/INTTRANSPORT/ Resources/336291-1227561426235/5611053-1229359963828/TP-6_LAC_Railways_ Concessions_spanish_web.pdf, ultimo acceso: 5 de Julio de 2017.

» UNIDAD DE ANÁLISIS DE POLÍTICA ECONÓMICA - UDAPE (2015) Diagnósticos Sectoriales. Transporte. La Paz: UDAPE, Disponible en: http://www.udape.gob. bo/portales_html/diagnosticos/diagnostic02015/TOMO\%20\%20IV\%2O-\%20 
SECTOR\%2OTRANSPORTE.pdf, último acceso: 5 de julio de 2017.

»VEIZAGA, Jorge (2014) Cambios estructurales en la economía boliviana (Retomando teorías clásicas para una perspectiva analítica alternativa), El Economista, Boletín del Colegio Departamental de Economistas de Cochabamba, Año 3, No 3, Diciembre de 2014.

»WARNER, Andrew (2014) Public Investment as an Engine of Growth, IMF Working Paper, WP/14/148, International Monetary Fund, disponible en: https:// www.imf.org/external/pubs/ft/wp/2014/wp14148.pdf, último acceso: 5 de Julio de 2017.

»WORLD BANK (2015) Bolivia - Systematic country diagnostic: rebalancing inclusive growth to deepen gains on poverty and inequality reduction. Washington, D.C.: World Bank Group. Disponible en: http://documents. worldbank.org/curated/en/741321468190740535/Bolivia-Systematic-countrydiagnostic-rebalancing-inclusive-growth-to-deepen-gains-on-poverty-andinequality-reduction, último acceso: 5 de Julio de 2017.

»ZELINSKY, Wilbur (1971) The hypothesis of the mobility transition, en Geographical Review Vol. 61, No 2, pp. 219-249.

\section{Jorge M. Veizaga R. / jmveizaga@gmail.com}

Licenciado en Economía, Especialista en demografía, Magister en Estudios de Población, Doctor en Estudios del Desarrollo. Investigador del Centro de Estudios de Población - Universidad Mayor de San Simón, Cochabamba - Bolivia. 